\title{
Bridging Interactions in Ceramics and Consequences on Crack Path Stability
}

\author{
Theo FETT, **** Gabriele RIZZI, * Dietrich MUNZ, ** Michael HOFFMANN, *** \\ Rainer OBERACKER ${ }^{* * *}$ and Susanne WAGNER *** \\ ${ }^{*}$ Forschungszentrum Karlsruhe, Institut fur Materialforschung II, Karlsruhe, Germany \\ **Universitat Karlsruhe, Institut fur Zuverlassigkeit von Bauteilen und Systemen, Karlsruhe, Germary \\ ***Universitat Karlsruhe, Institut fur Keramik im Maschinenbau, Karlsruhe, Germany
}

\begin{abstract}
An important fracture mechanics parameter governing path stability of growing cracks is the biaxiality ratio, i.e. the ratio of the T-stress and stress intensity factor. It is well known in general fracture mechanics that crack growth under positive biaxiality ratios is path-unstable. Any unavoidable mode-II loading must result in an increasing deviation from the initial straight crack plane. This holds for the most fracture mechanics test specimens used in tests on ceramic materials, for instance, edge-notched bending bars, CT, and DCB specimens. The theoretically predicted crack path stability is in disagreement with experimental findings reported in the literature on $\boldsymbol{R}$-curve measurements, where $\boldsymbol{R}$-curves were measured for crack lengths yielding high positive biaxiality ratios. Two possible reasons for this astonishing discrepancy between theory and experiments will be discussed.
\end{abstract}

[Received July 12, 2006; Accepted September 21, 2006]

Key-words : Biaxiality ratio, Crack bridging, Path stability, $R$-curve, $T$-stress

\section{Introduction}

Whereas crack growth in brittle materials is governed by the stress intensity factor, path stability during crack propagation is significantly affected by the constant stress term at the crack tip, the so-called T-stress. Taking into consideration the singular stress term and the first regular term, the near-tip stress field of a crack can be described by

$$
\sigma_{\mathrm{ij}}=\frac{K_{\mathrm{I}}}{\sqrt{2 \pi r}} f_{\mathrm{ij}}(\Theta)+\sigma_{\mathrm{ij}, 0}
$$

where $K_{\mathrm{I}}$ is the mode-I stress intensity factor and $f_{\mathrm{ij}}$ are the well-known angular functions $(r, \Theta=$ polar coordinates with the origin at the crack tip). In Cartesian coordinates, it holds

$$
\sigma_{\mathrm{ij}, 0}=\left(\begin{array}{cc}
T & 0 \\
0 & 0
\end{array}\right)
$$

where $T=\sigma_{x x, 0}$ is the so-called "T-stress" consisting of an $x$ component exclusively.

Apart from the singular stress term, the constant stress contribution acting over a longer distance from the crack tip may also influence fracture mechanics properties:

- In materials undergoing stress-induced phase transformations (e.g. transformation-toughened ceramics), the size of phase transformation zones at the crack tip is larger under positive than under compressive T-stress. Consequently, a steeper $R$-curve has to be expected for positive than for compressive T-stress (Ref. 1).

- A very similar effect has to be expected for microcracking zones in polycrystalline ceramics as well as for domain switching zones in piezoelectric materials (Ref. 2).

- Finally, local path stability during crack propagation is often discussed in terms of the T-stress (Ref. 3 ). This aspect shall be discussed here in detail for ceramic materials.

A crack of initial length $a_{0}$ is considered, which grows out of the initial straight plane by an angle of $\Theta_{0}$ (Fig. 1a)). The kink angle $\Theta_{0}$ may represent the influence of a disturbing mode-II loading caused by a small unavoidable misalignment of the loading arrangement. For small kink angles it holds

$$
\Theta_{0}=-\frac{2 K_{\mathrm{II}}}{K_{\mathrm{I}}}
$$

where $K_{\mathrm{I}}$ and $K_{\mathrm{II}}$ are the stress intensity factors for the initial crack situation.

In Ref. 3), Cotterell and Rice analyzed the local crack path stability (i.e. first deviations from the initial crack plane) for cracks with traction-free crack faces. Discussions in literature (Melin, ${ }^{4)}{ }^{5)}$ Pham et al. ${ }^{6)}$ ) deal with the global path stability after a longer crack extension. For our purpose only the first deviation from the initial straight crack plane is of interest. In this case, Cotterell and Rice analysis is an adequate description. It is based on the requirement of a disappearing mode-II stress intensity factor at the tip of the actual (grown) crack.

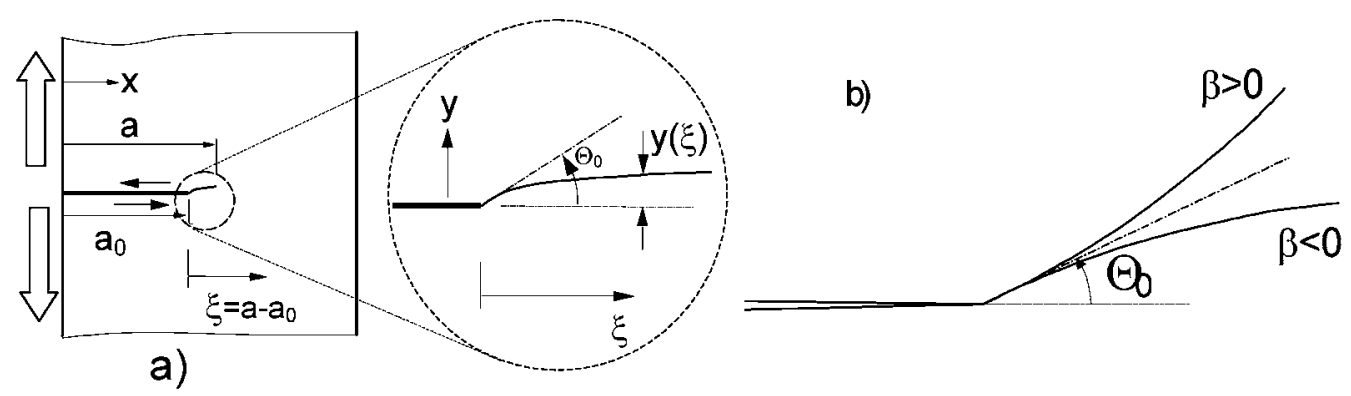

Fig. 1. a) Geometrical data of a crack growing under mode-I loading (vertical arrows) with a superimposed small mode-II disturbance (horizontal arrows), b) general influence of the T-stress after crack kinking under mixed-mode loading. 

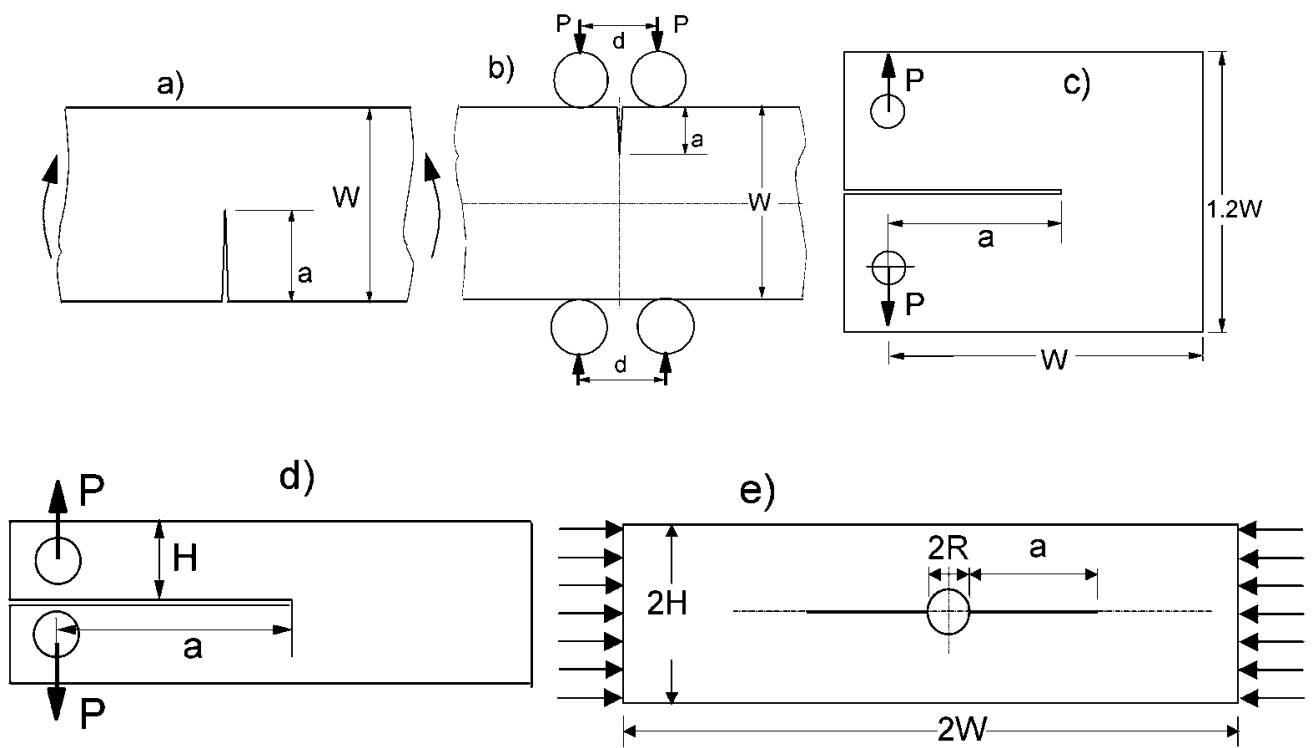

Fig. 2. Geometric data for several test specimens, a) bending test, b) bar under opposite cylinder loading, c) CT specimen, d) DCB specimen, e) DCDC specimen.

At small extensions $\xi$, the deviation from the initial crack plane, $y$, is given by

$$
\begin{aligned}
y(\xi)= & \frac{\Theta_{0}}{\beta^{2}} \frac{a_{0} \pi}{8}\left[\exp \left(\frac{8 \chi}{\pi} \beta^{2}\right) \operatorname{erfc}\left(-\beta \sqrt{\frac{8 \chi}{\pi}}\right)-1\right. \\
& \left.-\frac{4}{\pi} \beta \sqrt{2 \chi}\right], \chi=\left(a-a_{0}\right) / a_{0}
\end{aligned}
$$

with the biaxiality ratio $\beta$ proposed by Leevers and Radon ${ }^{7)}$

$$
\beta=\frac{T \sqrt{\pi a}}{K_{\mathrm{I}}}
$$

and normalized by a characteristic crack length (e.g. $a=a_{0}$ ). Although Eq. (4) is a solution for short crack extensions, this relation allows to discuss the basic influences on path stability. The most important conclusion of 3 ) is illustrated in Fig. 1b), namely, increasing deviation from the prescribed kink angle for $\beta>0$ and decreasing deviations for $\beta<0$.

From Eq. (4), it has to be expected that crack path stability is only guaranteed for $\beta<0$. In nearly all fracture mechanics test specimens, however, the T-stress and, consequently, the biaxiality ratio $\beta$ are positive, at least in the commonly used range of crack lengths. For a number of test specimens illustrated in Fig. 2, the biaxiality ratios $\beta$ are represented in Fig. 3 .

In Fig. 3a) the biaxiality ratios from 8) are plotted for the compact tension (CT) specimen, the 4-point bending specimen, and the opposite roller test. The solutions for the DCDC specimen (Fig. 3b)) and the DCB specimen (Fig. 3c)) are taken from 9) and 10). Most of the specimens show large regions with positive biaxiality ratios. There are two exceptions for standard test specimens used for ceramics, namely, small cracks in bending bars with a relative crack length $a / W$ $<0.35$ (specimen width $W$ ) and the DCDC specimen that shows strongly negative $\beta$ in the whole range of possible crack lengths. ${ }^{9)}$

In different crack-containing specimens, the path stability may differ strongly even at the same biaxiality ratio $\beta$. This may be illustrated for the cases of a CT specimen and a crack in a bar loaded by opposite cylinders.
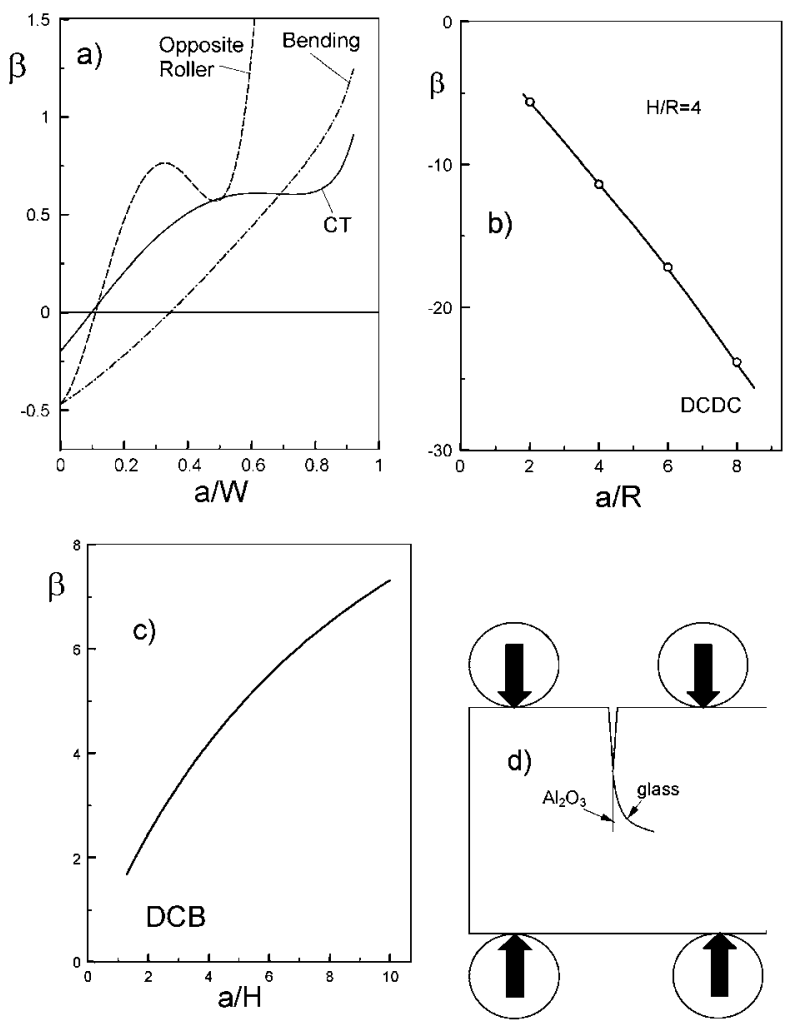

Fig. 3. a) Biaxiality ratio for 4-point bending tests, compact tension (CT) specimens, and opposite roller test; b) for the DCDC specimen, c) for the DCB specimen, d) crack paths in opposite roller fracture toughness tests.

Figure 4 shows the deviations of the crack from the linear propagation direction under the angle $\Theta_{0}$ that is prescribed by the disturbing mode-II loading contribution. The results for the case of a crack in a bar under opposite cylinder loading at two crack lengths $a_{0}$ are shown by the solid curves. Results for the CT specimen are given by the dashed curve. The curves are 


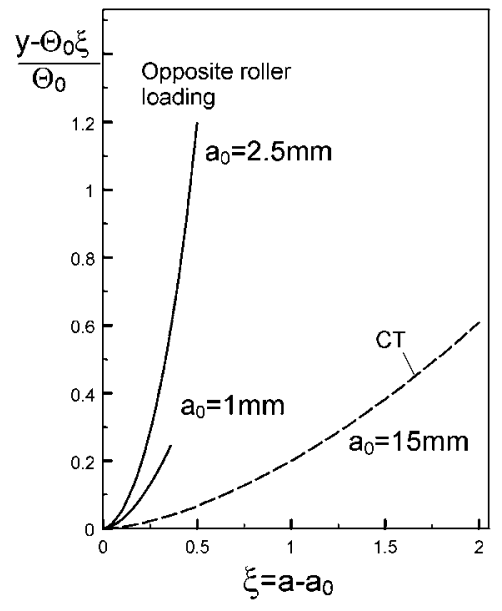

Fig. 4. Deviation of the crack path from the straight-line behaviour for a crack of length $a_{0}=1 \mathrm{~mm}$ and $2.5 \mathrm{~mm}$ in an opposite roller toughness test and a typical crack length of $a_{0}=15 \mathrm{~mm}$ in a CT specimen, plotted for maximum crack extensions of $1 / 3$ of the initial crack length.

Table 1. Ranking of Path Stability for Different Test Specimens with Typical Crack Lengths

\begin{tabular}{|c|c|c|c|}
\hline Test & Crack length $a_{0}$ & Biaxiality ratio $\beta$ & $\begin{array}{c}\text { Path instability parameter } \\
\beta / \sqrt{a_{0}}\left(\mathrm{~mm}^{-1.2}\right)\end{array}$ \\
\hline DCDC $(\mathrm{R}=0.5 \mathrm{~mm})$ & $2 \mathrm{~mm}$ & -12 & -8.5 \\
& $4 \mathrm{~mm}$ & -24 & -12 \\
\hline CT $(\mathrm{W}=30 \mathrm{~mm})$ & $15 \mathrm{~mm}$ & 0.6 & 0.155 \\
\hline Bending $(\mathrm{W}=4 \mathrm{~mm})$ & $1 \mathrm{~mm}$ & -0.14 & -0.14 \\
& $2 \mathrm{~mm}$ & 0.26 & 0.18 \\
& $3.5 \mathrm{~mm}$ & 1.05 & 0.56 \\
\hline DCB (H=12.5 mm) & $30 \mathrm{~mm}$ & 2.85 & 0.52 \\
\hline Opposite cylinder loading & $1 \mathrm{~mm}$ & 0.67 & 0.67 \\
$(\mathrm{~W}=4 \mathrm{~mm})$ & $2.5 \mathrm{~mm}$ & 1.7 & 1.07 \\
\hline
\end{tabular}

plotted for maximum crack extensions of $1 / 3$ of the initial crack length, having in mind that Eq. (4) is valid for small extensions exclusively.

For a better understanding of the effect of the parameters $\beta$ and $a_{0}$, the series expansion of Eq. (4) may be considered

$$
y(\xi)=\Theta_{0} \xi+\frac{8}{3 \pi} \sqrt{\frac{2}{a_{0}}} \beta \Theta_{0} \xi^{3 / 2}+O(\xi)
$$

(with $\xi=a-a_{0}$ ). It becomes obvious that the effect of the T-stress on the deviation from straight crack extension, $y(\xi)-$ $\Theta_{0} \xi$, is proportional to $\beta / \sqrt{a_{0}}$. At the same biaxiality ratio $\beta$, short cracks are significantly more sensitive to path instabilities than long cracks.

In Table 1 the parameter $\beta / \sqrt{a_{0}}$ is compiled for several test specimens and crack lengths. The best path stability is found for the DCDC specimen with negative values for $\beta / \sqrt{a_{0}}$. In principle, all specimens with positive $\beta$ and, consequently, positive $\beta / \sqrt{a_{0}}$ are path-unstable. The instability effect is small for the CT specimen and the edge-cracked bending bar with a short crack. Problems in path stability, however, have to be expected for deep cracks in bending bars, DCB specimens, and edge-cracked bars under opposite cylinder loading.

In literature, innumerable experimental results on $R$-curves are reported. In contrast to the expectation from Eq. (4), however, no crack-path instability worth mentioning was detected. This is not astonishing for DCDC tests, CT tests, and bending bars with short cracks because of their negative or moderately positive parameter $\beta / \sqrt{a_{0}}$ (Table 1$)$. Steinbrech et al., ${ }^{11)}$ for example, measured $R$-curves on coarse-grained alumina in bending up to relative crack lengths of about $a / W$ $=0.9$, where strong path instability has to be expected.

The same holds for tests with opposite roller loading ${ }^{12), 13)}$ and DCB tests, although only positive biaxiality ratios are involved in these tests.

For tests on materials without an $R$-curve (e.g. DCB tests on glass), it is well known from literature that guiding grooves are indispensable. In the case of an opposite roller test, cracks in glass became strongly path-unstable, whereas tests carried out with alumina ${ }^{13)}$ showed straight crack planes even after long crack extensions (Fig. 3d)). DCB test specimens as well as bars under opposite cylinder loading show maximum values of $\beta / \sqrt{a_{0}}$.

For coarse-grained materials, a shielding stress intensity factor term exists that shields the crack tip partially from the applied loads. This term is caused by crack bridging in the wake of a growing crack. For materials undergoing phase transformation in front of a crack tip (mostly accompanied by a change in volume), the shielding stress intensity factor is caused by residual stresses which reduce the stresses at the tip. In cases of materials without an $R$-curve, the externally applied load exclusively is responsible for the stress intensity factor $K_{\mathrm{I}}$ and the T-stress. In ceramics with $R$-curve effects caused by crack-face bridging (see e.g. ${ }^{14)}$ ), an additional crack loading by the bridging stresses will occur. In this case, the question arises: What are the T-term and the biaxiality ratio in the presence of bridging stresses?

\section{Influence of the shielding term on the biaxiality ratio}

\subsection{Basic relations}

The T-stress term caused by the externally applied mechanical load is denoted here as $T_{\text {appl }}$. In a material with an $R$-curve effect due to bridging stresses $\sigma_{\mathrm{br}}(x)<0$ acting in the crack wake (Fig. 5a)), a T-stress portion $T_{\text {br }}$ is created that can be computed by the Green's function (or weight function) technique. For bridging stresses disappearing at $x=a$, it results

$$
T_{\mathrm{br}}=\int_{0}^{a} t(x, a) \sigma_{\mathrm{br}}(x) \mathrm{d} x
$$

The Green's function $t$ in (Eq. 6) can be approximated by a two-terms expression. ${ }^{10), 15)}$ For the edge-cracked rectangular bar of width $W$, a three-terms Green's function was determined in 10) as

$$
\left.t=\frac{1}{a}\left(C_{0} \sqrt{1-x / a}+C_{1}(1-x / a)\right)^{3 / 2}\right)
$$

with the coefficients $C_{0}$ and $C_{1}$ expressed by

$$
\begin{aligned}
C_{0}= & \left\{1 5 \left(-0.3889+1.8706 \alpha-2.0012 \alpha^{2}-1.0544 \alpha^{3}\right.\right. \\
& \left.\left.+2.282 \alpha^{4}-0.3932 \alpha^{5}\right)\right\} /\left\{8(1-\alpha)^{2}\right\} \quad(7 \mathrm{~b} \\
C_{1}= & \left\{3 5 \left(0.5487-2.1127 \alpha-2.1180 \alpha^{2}+1.1845 \alpha^{3}\right.\right. \\
& \left.\left.-2.0864 \alpha^{4}+0.3932 \alpha^{5}\right)\right\} /\left\{8(1-\alpha)^{2}\right\}
\end{aligned}
$$

( $\alpha=a / W)$. Apart from the T-stress term $T_{\mathrm{br}}$, also the bridging stress intensity factor, $K_{\mathrm{br}}$, can be calculated from the bridging stresses. It holds

$$
K_{\mathrm{br}}=\int_{0}^{a} h(x, a) \sigma_{\mathrm{br}}(x) \mathrm{d} x
$$

with the well-known weight function $h(x, a)$ proposed by Bückner, ${ }^{16)}$ which is available in literature for most crack types (see e.g. ${ }^{10)}$ ). In contrast to the weight function for the T-stress, this weight function for stress intensity factors contains a singular term that dominates the near-tip behaviour. It reads 

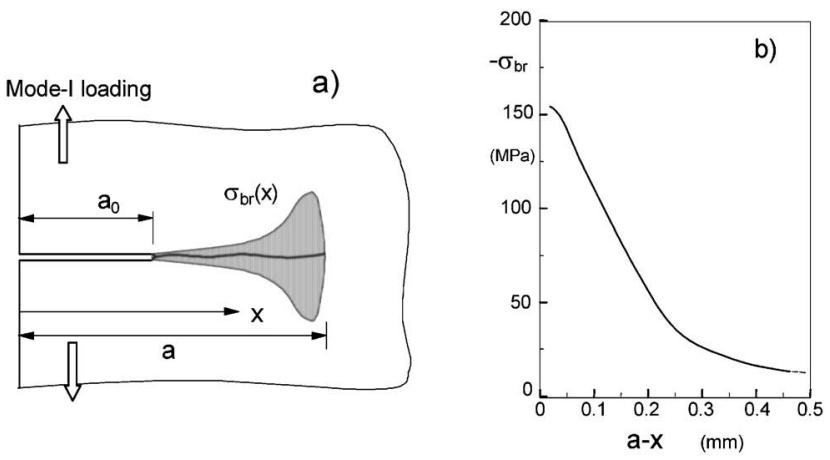

Fig. 5. a) Bridging stresses in the wake of a crack grown from a notch, b) bridging stress distribution in the wake of a crack in sintered reaction-bonded silicon nitride [17] after $\Delta a=0.52 \mathrm{~mm}$ crack extension.

$$
\mathrm{h}=\sqrt{\frac{2}{\pi a}}\left[\frac{1}{\sqrt{1-x / a}}+\sum_{n=0}^{\infty} D_{n}(1-x / a)^{n+1 / 2}\right]
$$

The total T-stress term, $T_{\text {total }}$, really present in the near-tip region is given by the sum of the applied and the bridging contributions, i.e. by

$$
T_{\text {total }}=T_{\text {appl }}+T_{\text {br }}
$$

If $K_{\text {appl }}$ denotes the stress intensity factor caused by the externally applied load, the total stress intensity factor $K_{\text {total }}$ representing the singular stresses near the crack tip is given by

$$
K_{\text {total }}=K_{\text {appl }}+K_{\text {br }}
$$

On the basis of the externally applied load, the (applied) biaxiality ratio $\beta_{\text {appl }}$ is given as

$$
\beta_{\text {appl }}=\frac{T_{\text {appl }} \sqrt{\pi a}}{K_{\text {appl }}}
$$

The real (total) biaxiality ratio can be written as

$$
\beta_{\text {total }}=\frac{T_{\text {total }} \sqrt{\pi a}}{K_{\text {total }}}=\frac{\left(T_{\text {appl }}+T_{\mathrm{br}}\right) \sqrt{\pi a}}{K_{\text {appl }}+K_{\mathrm{br}}} \neq \beta_{\text {appl }}
$$

Consequently, $\beta_{\text {total }}$ is different from $\beta_{\text {appl }}$, and path stability for cracks in materials with bridging effects must deviate from path stability for materials without a bridging behaviour. Since the total stress intensity factor during stable crack extension equals the crack-tip toughness, $K_{\text {total }}=K_{\mathrm{I} 0}$, Eq. (13a)) may be expressed as

$$
\beta_{\text {total }}=\frac{\left(T_{\text {appl }}+T_{\text {br }}\right) \sqrt{\pi a}}{K_{\mathrm{I} 0}}=\beta_{\text {appl }} \frac{K_{\text {appl }}}{K_{\mathrm{I} 0}}+\frac{T_{\text {br }}}{K_{\mathrm{I} 0}} \sqrt{\pi a}
$$

\subsection{Computation of $T_{\mathrm{br}}$ for a sintered reaction-bonded sili- con nitride}

As an example of application, let us consider a result from literature. In 17) the $R$-curve of a commercial, sintered reaction-bonded silicon nitride (SRBSN) was studied. This material has needle-like beta silicon nitride grains, 0.5 to $3 \mu \mathrm{m}$ wide with up to $10 \mu \mathrm{m}$ long, bonded by a second phase. Bars of $3 \times 4 \times 45 \mathrm{~mm}^{3}$ in dimension were cut and narrow notches were introduced with an initial depth of $a_{0}=1.03 \mathrm{~mm}$ by using the razor blade procedure. ${ }^{18), 19)}$ The notch was extended in a stiff loading device. After stable crack extensions of $0.227 \mathrm{~mm}$ and $0.52 \mathrm{~mm}$, COD measurements were carried out under load. From these results, bridging stresses were derived.

Figure 5b) shows the bridging stress distribution in the crack wake, $\sigma_{\mathrm{br}}(a-x)$. From this, $T_{\mathrm{br}}$ results by inserting
Table 2. T-Stress Portion due to Bridging Stresses and Biaxiality Ratios

\begin{tabular}{|llllll|}
\hline$\Delta a(\mathrm{~mm})$ & $a / W$ & $K_{\text {appl }}(\mathrm{MPa} \vee \mathrm{m})$ & $T_{\mathrm{br}}(\mathrm{MPa})$ & $\beta_{\text {appl }}$ & $\beta_{\text {total }}$ \\
0.227 & 0.314 & 5.1 & -1.20 & -0.0477 & -0.188 \\
0.52 & 0.388 & 5.9 & -1.48 & +0.0720 & 0.189 \\
\hline
\end{tabular}
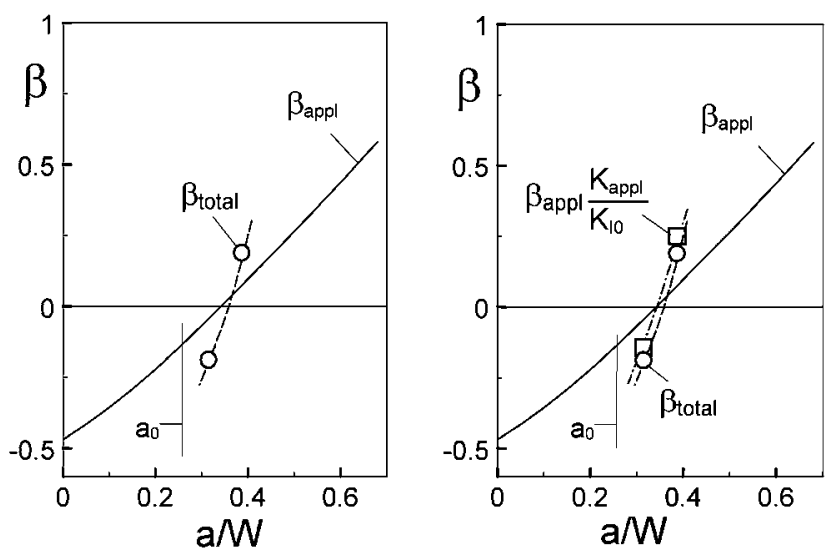

Fig. 6. a) Applied biaxiality ratio for an edge-cracked bending bar (solid curve) and total biaxiality ratios for the two bending results from [17] (circles), b) contribution of the ratio $K_{\text {appl }} / K_{\mathrm{I} 0}$ and of the bridging stresses.

the stress distribution into Eq.(6). The resulting bridging T-stresses are compiled in the fourth column of Table 2.

The biaxiality ratio $\beta_{\text {appl }}$ for the edge-cracked bar under bending load can be expressed as 8 )

$$
\begin{aligned}
\beta_{\text {appl }}= & \left(-0.469+1.2825 \alpha+0.6543 \alpha^{2}-1.2415 \alpha^{3}\right. \\
+0.07568 \alpha^{4} & /(\sqrt{1-\alpha})
\end{aligned}
$$

The values for the two crack lengths are given in the 5th column of Table 2.

In Fig. 6a) the applied and the total biaxiality ratios are plotted versus the relative crack length $a / W$. The main effect of an $R$-curve behaviour on the biaxiality ratio is represented by the ratio $K_{\text {appl }} / K_{\mathrm{I} 0}>1$ that enters Eq. (13b). The steepness of the function $\beta_{\text {total }}=f(a / W)$ is strongly increased compared to the function $\beta_{\mathrm{appl}}=f(a / W)$. The direct influence of the bridging tractions on the T-stress is of minor importance, as shown by the difference of the circles and squares in Fig. 6b). The region of negative biaxiality ratios is slightly extended from $0 \leq a / W \leq 0.34$ to $0 \leq a / W \leq 0.36$ by the contribution of bridging tractions. Roughly, it can be concluded that in the region of $\beta_{\text {appl }}<0$ (for the edge-cracked bending bar at $a / W<$ $0.34)$ the effective biaxiality ratio becomes stronger negative and crack path stability is promoted. In the region with $\beta_{\text {appl }}>$ 0 , an increased crack path instability has to be expected. Based on these results, Eq. (13b) can be approximated by

$$
\beta_{\text {total }} \cong \beta_{\text {appl }} \frac{K_{\text {appl }}}{K_{\mathrm{I} 0}}
$$

From the considerations made above, path stability can be concluded for a slightly extended range of crack lengths. This small effect is not sufficient to explain the path stability for larger cracks.

3. Influence of bridging interactions on $\mathrm{K}_{\|}$at the crack tip Let us assume a sharp crack of length a in a specimen, 

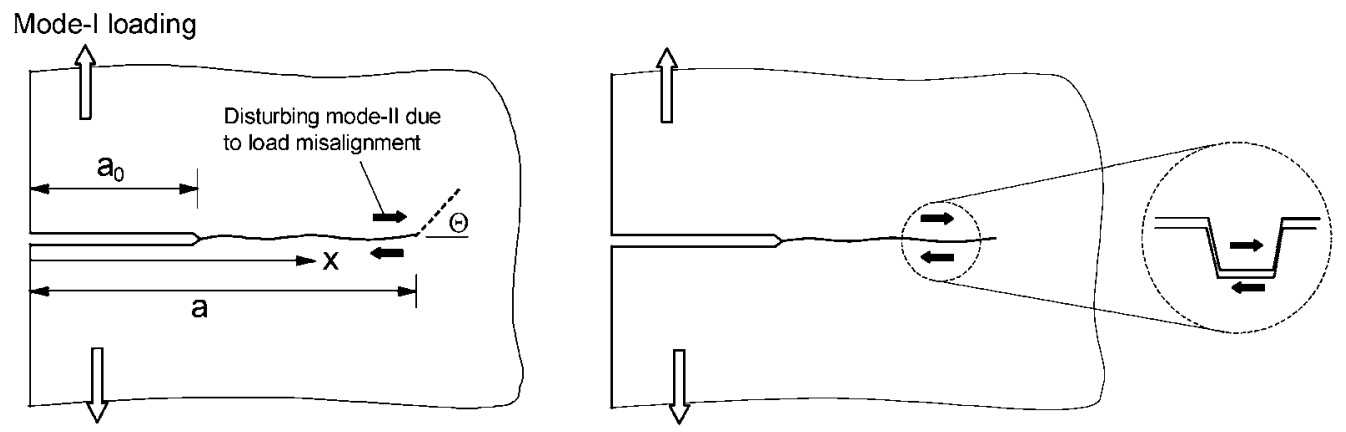

Fig. 7. Crack in a specimen grown from a notch, a) disturbance by a small mode-II load contribution, b) shielding against shear deformation by bridging interactions.

introduced by stable crack propagation starting from a notch of length $a_{0}$ (Fig. 7a). During further extension of this crack, a slight misalignment of the load application is assumed, resulting in a mode-II stress intensity factor $K_{\mathrm{II}, \text { appl }}$. During crack growth under an applied mode-I stress intensity factor $K_{\mathrm{I} \text {,appl }}$, it holds in the absence of subcritical crack growth that

$$
K_{\mathrm{I}, \mathrm{tip}}=K_{\mathrm{I}, \text { appl }}+K_{\mathrm{I}, \mathrm{br}}=K_{\mathrm{I} 0}
$$

where $K_{\mathrm{I}, \text { tip }}$ is the mode-I stress intensity factor portion acting at the crack tip, $K_{\mathrm{I}, \mathrm{br}}$ the portion carried by the "bridges", and $K_{\mathrm{I} 0}$ is the "crack tip toughness" necessary for maintaining stable crack extension.

The bridging interactions are also able to carry shear tractions, i.e. the material will exhibit a mode-II bridging stress intensity factor under mode-II loading here denoted by $K_{\mathrm{II}, \mathrm{br}}$. Similar to the mode-I bridging stress intensity factor, the mode-II part can be computed from the distribution of the shear tractions over the crack. It holds

$$
K_{\mathrm{II}, \mathrm{br}}=\int_{a_{0}}^{a} \tau_{\mathrm{br}}(x) h_{\mathrm{II}}(x) d x
$$

with the weight function $h_{\text {II }}$ for shear loading. The actual mode-II crack tip stress intensity factor $K_{\text {II,tip }}$ results from

$$
K_{\mathrm{II}, \mathrm{tip}}=K_{\mathrm{II}, \text { appl }}+K_{\mathrm{II}, \mathrm{br}}
$$

and the crack kink angle $\Theta$ (in contrast to Eq. (3)) from

$$
\Theta=-2 \frac{K_{\mathrm{II}, \text { tip }}}{K_{\mathrm{I} 0}}
$$

In the absence of any crack-face interlocking, the applied mode-II loading causes shear displacements $\delta_{x, \text { appl }}$ between the two crack surfaces. In the presence of bridging effects with crack-face interlocking, these displacements are (at least partially) suppressed and generate locally concentrated shear forces at the location of the bridging interactions (Fig. 7b)). Similar to the treatment of mode-I loading, a continuously distributed shear stress averaging the local crack face interactions is assumed for the bridging effect under mode-II loading.

The shear stresses $\tau$ are now assumed to be proportional to the suppressed applied shear displacements $\delta_{x, \text { appl }}$ caused by the externally applied mode-II stress intensity factor $K_{\text {II,appl }}$ and a function $f$ that represents the intensity of the crack face interactions. This function has its maximum value (here chosen to be $f=1$ ) at the crack tip, where the crack surface linking effects are fully present, and decreases monotonously with increasing distance from the crack tip, because the linking effects disappear due to increasing actual crack opening displacement $\delta_{y}$ caused by the mode-I loading. Consequently, the shear interactions must decrease with $\delta_{y}$, i.e. with increasing crack tip distance $a-x$.

This leads to the relation

$$
\tau=-A \delta_{x, \text { appl }} f\left(\delta_{y}\right)
$$

with an a priori unknown material parameter $A>0$. The negative sign in Eq. (18) implies that the shear stresses act against $\delta_{x, \text { appl }}$. Similar to the treatment of mode-I bridging interactions with statistically distributed interaction lengths, ${ }^{20)}$ the function $f$ may be represented by

$$
f\left(\delta_{y}\right)=\exp \left(-\delta_{y} / \delta_{y 0}\right)
$$

that fulfills the required conditions for $f$. The parameter $\delta_{y 0}$ is a characteristic displacement. It is expected to be in the order of a percentage of the mean grain size $g_{m}$, i.e.

$$
\delta_{y 0}=\lambda g_{\mathrm{m}}, \quad \lambda<1
$$

Under near-tip conditions, the displacements $\delta_{x, \text { appl }}$ and $\delta_{y}$ during stable crack extension can be expressed by the Irwin relations

$$
\begin{aligned}
& \delta_{x}=\sqrt{\frac{8}{\pi}} \frac{K_{\mathrm{II}, \mathrm{appl}}}{E^{\prime}} \sqrt{a-x} \\
& \delta_{y}=\sqrt{\frac{8}{\pi}} \frac{K_{\mathrm{I} 0}}{E^{\prime}} \sqrt{a-x}
\end{aligned}
$$

$\left(E^{\prime}=\right.$ plane strain modulus $)$. Inserting this into Eqs. (18) and (19) gives the bridging stress distribution $\tau=\tau_{\mathrm{br}}(x)$

$$
\begin{aligned}
\tau= & -A \sqrt{\frac{8}{\pi}} \frac{K_{\mathrm{II}, \mathrm{appl}}}{E^{\prime}} \sqrt{a-x} \\
& \exp \left[-\sqrt{\frac{8}{\pi}} \frac{K_{\mathrm{I} 0}}{\delta_{y 0} E^{\prime}} \sqrt{a-x}\right]
\end{aligned}
$$

Together with the near-tip weight function

$$
h_{\mathrm{II}}=\sqrt{\frac{2}{\pi(a-x)}}
$$

the integral of Eq. (15) can be evaluated and it results

$$
\begin{aligned}
K_{\mathrm{II}, \mathrm{br}}= & -A \frac{\delta_{\mathrm{y} 0}{ }^{2} E^{\prime}}{K_{\mathrm{I} 0}{ }^{2}} K_{\mathrm{II}, \mathrm{appl}}\left(1-\left(1+D \sqrt{a-a_{0}}\right)\right. \\
& \left.\times \exp \left(-D \sqrt{a-a_{0}}\right)\right), \quad D=\sqrt{\frac{8}{\pi}} \frac{K_{\mathrm{I} 0}}{\delta_{y 0} E^{\prime}}
\end{aligned}
$$

A power series expansion reads 


$$
\begin{aligned}
K_{\mathrm{II}, \mathrm{br}}= & -A \frac{\delta_{y 0}^{2} E^{\prime}}{K_{\mathrm{I} 0}^{2}} K_{\mathrm{II}, \mathrm{appl}}\left[\frac{1}{2} D^{2}\left(a-a_{0}\right)\right. \\
& \left.-\frac{1}{3} D^{3}\left(a-a_{0}\right)^{3 / 2}+O\left(\left(a-a_{0}\right)^{2}\right)\right]
\end{aligned}
$$

so for small crack extensions it holds

$$
K_{\mathrm{II}, \mathrm{br}} \cong-\frac{4}{\pi} A \frac{a-a_{0}}{E^{\prime}} K_{\mathrm{II}, \mathrm{appl}}
$$

Equation (16) allows to relate the crack-tip mode-II stress intensity factor to the applied one. The crack-tip stress intensity factor $K_{\text {II,tip }}$ results as

$$
K_{\mathrm{II}, \mathrm{tip}}=\left\{\begin{array}{cc}
\left(1-\frac{4}{\pi} A \frac{a-a_{0}}{E^{\prime}}\right) K_{\mathrm{II}, \mathrm{appl}} & \text { for } \frac{4}{\pi} A \frac{a-a_{0}}{E^{\prime}} \leq 1 \\
0 & \text { for } \frac{4}{\pi} A \frac{a-a_{0}}{E^{\prime}}>1
\end{array}\right.
$$

Already after a very short crack extension $\left(a-a_{0}\right)$, the cracktip stress intensity factor $K_{\mathrm{II}, \text { tip }}$ disappears. This is expected, because a grain that gives rise to crack-surface linking seems to be much more resistant to shear than to tension. From Eqs. (17) and (25), it can be concluded that small disturbing mode-II stress intensity factors $K_{\text {II,appl }}$ cannot yield crack kinking for materials with a bridging behaviour. For large externally applied $K_{\mathrm{II}}$, a value $K_{\mathrm{II} \text {,tip }}$ may increase from zero, for instance, when shear bridges are destroyed.

In all coarse-grained ceramics, crack interlocking behind the crack tip may contribute to the $K_{\mathrm{II}}$ shielding stress intensity factor. Since also PZT ceramics, for instance, are coarsegrained with typical grain sizes of $5-10 \mu \mathrm{m}$, a mode-II bridging effect has to be expected in principle, although the mode-I shielding stress intensity factor is predominantly caused by the residual stresses.

\section{Summary}

In the present study, attention was drawn to the general problem of crack path stability in ceramics. A theoretical analysis based on T-stress and biaxiality ratio $\beta$ showed that pathstable crack extension can be understood for a material that shows crack face interactions.

The biaxiality ratio is the fracture mechanics parameter governing local path stability of growing cracks. If this parameter is positive, no stable crack propagation can occur. From the data of Table 1 serious problems in path stability have to be expected

-for bending tests with a relative crack length $a / W>0.8$,

-for DCB-specimens, and

-for bars with opposite cylinder loading

In contrast to this expectation, it is well known for brittle materials with an $R$-curve behaviour that cracks may propagate also in crack length regions with positive biaxiality ratios. In the present paper, two possible effects were studied as potential reasons for this astonishing path stability:
- By consideration of the bridging stresses caused by mode-I crack opening displacements, it was found that the effective biaxiality ratio becomes more negative in that region, where the biaxiality ratio for a material without an $R$-curve behaviour already is negative. Consequently, crack path stability is promoted in this region. Unfortunately, the regions in which positive and negative biaxiality ratios occur are hardly affected.

- A mode-II shielding effect due to crack face interactions was identified as the main reason for path stability. It ensures $K_{\mathrm{II}}=0$ at the crack tip.

The second point explains the experimental findings in literature.

Acknowledgment The authors would like to thank the Deutsche Forschungsgemeinschaft DFG for financing parts of this work within the SFB 483.

\section{References}

1) Giannakopoulos, A. E. and Olsson, M., J. Am. Ceram. Soc., Vol. 75, pp. 2761-2764 (1992).

2) Fett, T., Glazounov, A., Hoffmann, M. J., Munz, D. and Thun, G., Engng. Fract. Mech., Vol. 68, pp. 1207-1218 (2001).

3) Cotterell, B. and Rice, J. R., Int. J. Fract., Vol. 16, pp. 155-169 (1980).

4) Melin, S., Int. J. Fract., Vol. 50, pp. 293-300 (1991).

5) Melin, S., Int. J. Fract., Vol 114, pp. 259-265 (2002).

6) Pham, V.-B., Bahr, H.-A., Bahr, U., Fett, T. and Balke, H., Int. J. Fract., to be published.

7) Leevers, P. S. and Radon, J. C., Int. J. Fract., Vol. 19, pp. 311-325 (1982).

8) Fett, T., T-Stress and Stress Intensity Factor Solutions for 2Dimensional Cracks, VDI-Verlag, 2002, Düsseldorf.

9) Fett, T., Rizzi, G. and Munz, D., Engng. Fract. Mech., Vol. 72, pp. 145-149 (2005).

10) Fett, T. and Munz, D., "Stress Intensity Factors and Weight Functions," Computational Mechanics Publications, Southampton, UK (1997).

11) Steinbrech, R., Reichl, A. and Schaarwächter, W., J. Am. Ceram. Soc., Vol. 73, 2009-2015 (1990).

12) Fett, T., Glazounov, A., Hoffmann, M.J., Munz, D., Thun, G., Engng. Fract. Mech., Vol. 68, pp. 1207-1218 (2001).

13) Fett, T., Munz, D. and Thun, A., Engng. Fract. Mech., Vol. 68, pp. 29-38 (2001).

14) Munz, D. and Fett, T., "CERAMICS, Failure, Material Selection, Design," Springer-Verlag, Berlin (1999).

15) Wang, X., Engng. Fract. Mech., Vol. 70, pp. 731-756 (2003).

16) Bueckner, H., ZAMM, Vol. 50, pp. 529-546 (1970).

17) Fett, T., Munz, D., Kounga Njiwa, A. B., Rödel, J. and Quinn, G. D., J. Eur. Ceram. Soc., Vol. 25, pp. 29-36 (2005).

18) Nishida, T., Pezzotti, G., Mangialardi, T. and Paolini, A. E., "Fracture Mechanics Evaluation of Ceramics by Stable Crack Propagation in Bend Bar Specimens," Fract. Mech. Ceram. 11", Eds. Bradt, R.C. Hasselman D. P. H. Munz, D. Sakai, M. Shevchenko V. Y.) (1996) pp. 107-114.

19) Kübler, J., Fracture toughness using the SEVNB method: Preliminary results, Ceramic Engineering \& Science Proceedings, Vol. 18, pp. 155-162 (1997).

20) Fett, T. and Munz, D., J. Eur. Ceram. Soc., Vol. 15, pp. 377-383 (1995). 